
\title{
25 Research Soure \\ Rhizosphere Microbiome of Forest Trees Determines Their Resistance to Soil-borne Pathogens
}

Li Yu

Nanjing Forestry university

Haiyun Zi

Nanjing Forestry university

Hongguang Zhu

Nanjing Forestry university

Yangwenke Liao

Nanjing Forestry university

Xiaogang Li ( $\nabla$ xgli@njfu.edu.cn )

Nanjing Forestry university https://orcid.org/0000-0002-7976-1122

\section{Research Article}

Keywords: Rhizosphere microbiome, Fungal pathogens, Forest health, Bio-stress, Root exudates

Posted Date: January 17th, 2022

DOI: https://doi.org/10.21203/rs.3.rs-1234640/v1

License: (c) (1) This work is licensed under a Creative Commons Attribution 4.0 International License. Read Full License 


\section{Abstract}

Background and aims

The ability of plants to cope with environmental pressure and the interaction between rhizosphere microorganisms and host trees play an important role in the stability and function of forest ecosystems. Beneficial microbes recruited to the plant rhizosphere and stably association with tree roots can potentially reduce biotic stress, but the biochemical processes involved in coping with pathogen attack are not fully understood. Here, we aimed to investigate the ecology process of rhizosphere microbiota from four broad-leaved and three coniferous tree varieties involving in the suppression of soil-borne fungal pathogens.

Methods

We used separation cultivation and in vitro antagonistic experiments to investigate the inhibitory effects of rhizosphere microbiome on pathogenic fungi. Rhizosphere microbiome was then sequenced using the Illumina MiSeq platform, and root exudates of trees were measured by gas chromatography-mass spectrometry (GC-MS).

Results

Rhizosphere microbes from seven tree varieties had strong inhibitory effects on fungal pathogens, nevertheless, there were significant differences in their capacity. The dissimilarities in rhizosphere bacterial communities that were significantly correlated with phylogenetic distance of trees had a greater influence on suppression of pathogens compared with microbial abundance and diversity. Combined analysis of a random forest model and co-occurrence networks, revealed a cooperative relationship between key groups that were positively associated with inhibition of fungal pathogens in the tree rhizosphere. This process was further strengthened by specific metabolites secreted by tree roots.

\section{Conclusions}

In general, the rhizosphere microbiota of seven tree species had different inhibitory effects on fungal pathogens, and the cooperative relationship within the rhizosphere microbial community plays an important role in maintaining trees resistance to soil pathogens stress.

\section{Introduction}

Forests are primary, dynamic ecosystems with vital roles in maintaining ecological and economic functions, such as sequestering carbon (Moomaw et al. 2020), environmental conditioning (Rudel et al. 2020), and supplying wood and bioenergy (Nepal et al. 2019). Due to their long lifespan, trees are susceptible to external abiotic and biotic stresses such as drought, salinity, herbivore and pathogen attack (Rodriguez et al. 2019; Zamora Ballesteros et al. 2019; Oliva et al. 2020; Pagán et al. 2022), which seriously compromise tree health and the stability and function of forest ecosystems on a global scale 
(Reddy et al. 2013). Soil-borne pathogens are especially harmful as they infect tree roots, limiting growth and increasing susceptibility to other disease occurrences. As described by Ben Amira et al. (2017) and Chliyeh et al. (2017), Fusarium oxysporum is known to be responsible for olive root rot, causing premature death of the infected plants and large economic losses. Accordingly, understanding the mechanisms linking tree host resistance to stress from soil-borne pathogens is needed to gain insight into forest ecosystem homeostasis, as well as the relationship between rhizosphere interactions and the establishment of a sustainable forest ecosystem.

Soil microbes present in the rhizosphere, the narrow zone around the plant roots, bridge the interactions between the plant and the soil (Raaijmakers et al. 2009), and have close-knit affiliations with plant growth and health via nutrient transformation, disease resistance and substrate metabolism (Mendes et al. 2013; Bakker et al. 2020a; Kong et al. 2020; Wei et al. 2020). Studies on lettuce (Simko et al. 2013), barley (Schmalenbach et al. 2008), wheat (Yin et al. 2021), strawberry (Cha et al. 2015) and Arabidopsis thaliana (Berendsen et al. 2018a) showed that rhizosphere microbiota regulated by breeding and domestication play vital roles in plant resistance to soil pathogens. Meanwhile, growth-promoting and antifungal microbes in the plant rhizosphere produce antifungal compounds and metabolites that can alter the synthesis of root exudates to improve plant resistance to pathogen invasion. However, for most of the agricultural crops employed in previous studies, their short growth cycle imposed restrictions on the stabilization of the rhizosphere microbiota, and thus their roles in plant resistance were readily disturbed by environmental conditions (Ryan et al. 2009; Kokalis-Burelle et al. 2017). This made it difficult for an in-depth understanding of how the rhizosphere microbiota influenced plant resistance, as little was known about the importance of intrinsic selection of plants and the influence of environmental filtering on the composition of the rhizosphere microbiota during the limited growth cycle. On the contrary, trees have established the characteristics of the rhizosphere microbiome and plant traits as a consequence of the periodic interactions between trees and soil microbes (Hu et al. 2018; Mercado-Blanco et al. 2018), in supporting resistance to biotic stress from soil-borne pathogens.

Optimization of the microbial community in the tree rhizosphere could be an effective approach for enhancing forest resistance and health (Rahman et al. 2018; Hu et al. 2020; Trivedi et al. 2020b). There is a functional redundancy in the microbial community of an ecosystem, but key microbial species can determine the resistance of a community to pathogen stress through interaction with different species and their anti-pathogen capability (Jousset et al. 2017). Cooperation or competition between microbes significantly affects community stability and function. For instance, the synergistic effects of microbial interaction can increase the production of fungistatic compounds, while other microbes compete with them for nutrients and living space (Veras et al. 2012; Li et al. 2019). Determining the mechanism of how key microbes affect interaction is necessary to understand the rhizosphere microbiota involvement in trees' resistance to pathogens. This process is regulated by substances secreted by tree roots in the rhizosphere (Baetz and Martinoia, 2014; Corral Lugo et al. 2016), and the relationship between the composition of the rhizosphere microbial communities and root exudates reflects the ability of the tree rhizosphere to respond to soil biotic stress. 
We hypothesized that the composition of the rhizosphere microbiota recruited by tree roots would determine plant resistance to soil-borne pathogens. In the current study, we aimed to test this hypothesis and to unravel the mechanisms involved. Accordingly, we selected seven major afforestation tree varieties in China, and performed co-culture experiments that challenged soil-borne pathogens with rhizosphere microbiota to assess trees resistance on soil bio-stress. The study found that under pathogen stress, some key microbes that had cooperative relationships with the residual taxa in the tree rhizosphere strengthened resistance to pathogen invasion. Simultaneously, specific compounds in tree root exudates stimulated key rhizosphere bacteria to cooperate in suppressing undesirable microbes.

\section{Materials And Methods}

\subsection{Site descriptions and soil sampling}

The sampling site was located on the tree plantations of Nanjing Forestry University campus $\left(32^{\circ} 05^{\prime} \mathrm{N}\right.$, $118^{\circ} 80^{\prime} \mathrm{E}$ ). The tree plantations were established 40 years ago, with the characteristics of bulk distribution. Across the plantations we chose four broadleaf trees, pterocarya (Pterocarya stenoptera), Italian poplar (Populus euramericana cv.'I-214'), camphor tree (Cinnamomum camphora) and liriodendron (Liriodendron chinense x tulipifera), and three conifers, cypress (Sabina chinensis L., Ant. cv. Kaizuca), metasequoia (Metasequoia glyptostroboides), and cedar (Cedrus deodara). These varieties include an evergreen broadleaf tree, an evergreen conifer, a deciduous conifer and a deciduous broadleaf tree. The site has a subtropical monsoon climate with an annual average temperature of $15.4^{\circ} \mathrm{C}$ and precipitation of $1106.5 \mathrm{~mm}$. The soil type was classified as yellow-brown and the main physicochemical properties were: total nitrogen (TN) $1.24 \mathrm{~g} \cdot \mathrm{kg}^{-1}$, total phosphorus (TP) $0.78 \mathrm{~g} \cdot \mathrm{kg}^{-1}$, total potassium (TK) $14.5 \mathrm{~g} \cdot \mathrm{kg}^{-1}$ and available potassium (AK) $157.9 \mathrm{mg} \cdot \mathrm{kg}^{-1}$.

For sampling, trees more than 20 years old and with a density of $\geq 3$ were employed to avoid the effects of other varieties and vegetation. After removing the surface litter, the roots of each tree were identified by digging down about up to $20 \mathrm{~cm}$ around the trees for a radius of $1 \mathrm{~m}$. Rhizosphere soil particles adhering to the roots were collected into sterile plastic bag with a sterile brush. For each plot of trees, four soil samples were collected based on different direction of the trees, and mixed to yield a composite sample. Three plots across the campus separated by a distance of $>100 \mathrm{~m}$ were sampled for each tree variety, for a total of 21 rhizosphere soil samples collected. After sieved $(2 \mathrm{~mm})$, the rhizosphere soils of each plot were divided into two portions. One portion was stored at $4^{\circ} \mathrm{C}$ for cultivation experiments and determination of rhizosphere exudates, and the other was stored at $-20^{\circ} \mathrm{C}$ for DNA extraction.

\subsection{In vitro suppression of fungal pathogens by rhizosphere soil}

Fusarium oxysporum, Rhizoctonia solani and Alternaria alternata were obtained from the Forest Pathology Laboratory of Nanjing Forestry University. These are typical fungi causing tree diseases. The suppression of fungal pathogens by rhizosphere soils was determined by in vitro microcosm tests for 
separation and antagonism (Fig. S1). Rhizosphere soil bacterial suspensions were prepared according to the method of Hol et al. (2015). Briefly, $5 \mathrm{~g}$ (dry weight equivalent) of fresh rhizosphere soil and $45 \mathrm{ml}$ of phosphate buffer $\left(\mathrm{KH}_{2} \mathrm{PO}_{4}, 1 \mathrm{~g} \cdot \mathrm{L}^{-1}, \mathrm{pH}=6.5\right)$ were agitated on a rotary shaker at $4^{\circ} \mathrm{C}$ and $150 \mathrm{rpm}$ for 1.5 $\mathrm{h}$. The suspensions were then sonicated for $1 \mathrm{~min}$ at $47 \mathrm{kHz}$ twice and shaking for $0.5 \mathrm{~h}$. The suspensions were filtered through a 5 - $\mu \mathrm{m}$ filter to remove a large proportion of fungal propagules before testing in the separation and in vitro antagonism experiment.

For the separation cultivation experiments, the bioassays were performed in sterile Petri dishes $(9 \mathrm{~cm}$ diameter) containing top and bottom areas (Fig. S1a). Before the cultivation experiments, a fungal agar plug (8 mm diameter) was transferred to potato dextrose agar (PDA) (Table S1) and placed in an incubator at $28^{\circ} \mathrm{C}$ for three days in the dark. An inverted assay as described in Garbeva et al. (2013b) was used. Briefly, a plug containing pathogenic fungal hyphae was inoculated in the bottom of a Petri dish with PDA, and incubated at $28^{\circ} \mathrm{C}$ for $24 \mathrm{~h}$. A layer of nutrient agar (beef extract peptone medium, NA) was poured into the lid of the Petri dish, and after hardening, $200 \mu \mathrm{l}$ aliquots of bacterial suspension were evenly spread on the NA (Table S1). The top of the plate was placed on the bottom, sealed with Parafilm and incubated at $28^{\circ} \mathrm{C}$ until the control PDA plates were filled with mycelia. In this way, the fungi to be tested were exposed to any antifungal substances produced by bacteria in the upper compartment. After incubation, the extension of fungal hyphae was determined and compared with that in control plates (fungi on PDA without bacteria).

For the in vitro antagonistic experiment, $60 \mu$ of suspension was inoculated evenly on a piece of sterile filter paper $(1.8 \mathrm{~cm} \times 4.8 \mathrm{~cm})$ on one side of NA medium. After three days, a PDA plug (8 $\mathrm{mm}$ diameter) containing fungal hyphae was placed on the NA, $2 \mathrm{~cm}$ away from the filter paper (Fig. S1b). The plate was sealed with Parafilm and incubated at $28^{\circ} \mathrm{C}$. The extension of fungal hyphae was measured after 72 $\mathrm{h}$ and compared with control plates (sterile water instead of bacterial suspension). Each treatment was repeated three times. The fungal pathogens were exposed to the secretions produced by the bacterial communities on the filter paper.

\subsection{Suppression of Fusarium oxysporum spore germination by rhizosphere soil}

A spore suspension was prepared as follows. Fungal hyphae were picked from $F$. oxysporum cultures on $\mathrm{PDA}$, and put into potato dextrose medium and agitated at $180 \mathrm{rpm}$ for $3-5$ days at $25^{\circ} \mathrm{C}$. Following Chen et al. (2020), spore suspensions were diluted in sterile deionized water to a concentration of $1 \times 10^{4}$ conidia/ml. Next, $270 \mu \mathrm{l}$ of rhizosphere bacterial suspension (prepared as previously described) were mixed with $30 \mu \mathrm{l}$ of spore suspension in sterile $0.5 \mathrm{ml}$ centrifuge tubes and incubated at $28^{\circ} \mathrm{C}$ in the dark. After $12 \mathrm{~h}$, spore germination was determined microscopically by counting spores in 10 fields per well (400x). A spore was considered germinated if the germ tube length was as long as the length of the spore. Addition of an equal volume of sterile deionized water to the fungal spores instead of the bacterial suspension was used as control. Each treatment was repeated three times. 


\subsection{Soil DNA extraction and high-throughput sequencing of 16S rRNA}

Total DNA was extracted from $0.3 \mathrm{~g}$ samples of rhizosphere soil (21 samples) using the Fast DNA spin kit for soil (MP Biomedicals, Santa Ana, CA, USA). The final concentration and quality of DNA were confirmed using a NanoDrop5000 spectrophotometer (Thermo Scientific, Wilmington, USA). The V3-V4 region of the $16 \mathrm{~S}$ rRNA gene was amplified using the universal primer pairs $338 \mathrm{~F} / 518 \mathrm{R}\left(5^{\prime}-\right.$ ACTCCTACGGGAGGCAGCAG-3')/(5'-ATTACCGCGGCTGCTGG-3') (Fierer et al. 2005b). Sample-specific 7bp barcodes were incorporated into the primers for multiplex sequencing. All PCR reactions were performed in $24 \mu \mathrm{l}$ reactions containing $5 \mu \mathrm{l}$ of $5 \mathrm{x}$ reaction buffer (Takara Bio, Otsu, Japan), $2 \mu \mathrm{l}$ of each dNTP $(2.5 \mathrm{mM}), 1 \mu \mathrm{l}$ of each primer $(10 \mu \mathrm{M}), 1 \mu$ l of DNA template, $0.25 \mu$ l DNA polymerase (Q5), and $14.75 \mu \mathrm{l}$ of $\mathrm{ddH}_{2} \mathrm{O}$. After purification using Vazyme VAHTSTM DNA clean beads (Vazyme, Nanjing, China), the pooled 16S rRNA gene samples were sequenced using the Illumina MiSeq platform at Shanghai Personal Biotechnology Co., Ltd (Shanghai, China). A resampled ASV table was formed for subsequent bacterial diversity analysis.

After sequencing, the raw data were analyzed using the QIIME2 (Bokulich et al. 2018) pipeline (https://docs.qiime2.org/2019.7/tutorials/overview/). Low-quality sequences ( $<200 \mathrm{bp}$ in length or those not matching the primer and barcode) were removed, and the remaining sequences were aligned against the database release 13.8 (http://greengenes.secondgenome.com/). Sequences were quality-filtered, denoised, merged and chimeras removed using the DADA2 plugin (DeSantis et al. 2006). ASVs (amplicon sequence variants) were identified by each de-duplicated sequence produced after quality control with DADA2. Lastly, the ASV tables for each sample were summarized at various levels of taxonomic hierarchical structure.

\subsection{Quantitative real-time PCR Assays (qPCR)}

Total bacterial abundance in plant rhizosphere was determined by quantitative real-time PCR (qPCR). The reactions were performed in a $20 \mu \mathrm{L}$ volume containing $2 \mu \mathrm{l}$ of template DNA, $10 \mu \mathrm{l}$ of $2 x$ SYBR® Green master-mix, $0.2 \mu \mathrm{l}$ each of positive and reverse primer, and $7.6 \mu \mathrm{L}$ of double distilled water $\left(\mathrm{ddH}_{2} \mathrm{O}\right)$. The PCR procedure was as follows: pre-denaturation at $95^{\circ} \mathrm{C}$ for $15 \mathrm{~min}$, denaturation at $95^{\circ} \mathrm{C}$ for $1 \mathrm{~min}$, annealing at $57^{\circ} \mathrm{C}$ for $30 \mathrm{~s}$, elongation at $72^{\circ} \mathrm{C}$ for $1 \mathrm{~min}, 40$ cycles. Dissolution curves and agarose gel electrophoresis were used to verify the specificity of amplification. The abundance of the target microbial groups was expressed as target gene copies per gram of soil. Each plate included triplicate reactions per DNA sample and the appropriate set of standards. Melting curve analysis of the PCR products was conducted following each assay to confirm that the fluorescence signal originated from specific PCR products and not from primer-dimers or other artifacts.

\subsection{Analysis of root exudates by gas chromatography-mass spectrometry (GC-MS)}


Root exudates were obtained by the method of Duan (2014). Rhizosphere soil was added to $85 \%$ ethanol at a soil-to-ethanol ratio of $1: 3(\mathrm{w} / \mathrm{v})$ in a centrifuge tube, and mixed on a rotary shaker at $20^{\circ} \mathrm{C}, 2600 \mathrm{rpm}$ for $24 \mathrm{~h}$. The suspension was then centrifuged at $3500 \mathrm{rpm}$ for $15 \mathrm{~min}$ at $20^{\circ} \mathrm{C}$, and concentrated in a rotary evaporator to remove the ethanol. The suspension was extracted twice with ethyl acetate (1:1) as a neutral component. After adjusting the $\mathrm{pH}$ of the aqueous phase to 3.0 with I $\mathrm{M} \mathrm{HCl}$, it was extracted twice with the same amount of ethyl acetate as an acidic component. Afterwards, the $\mathrm{pH}$ of the water phase was adjusted to 8.0 with $1 \mathrm{M} \mathrm{NaOH}$, and then extracted twice with the same amount of ethyl acetate as an alkaline component. Finally, the acidic, neutral and alkaline ethyl acetate phases were combined as the extract of tree root exudates for GC-MS.

The derivatives were analyzed using a Trace ISQ 1300 gas chromatograph (Thermo-Fisher Scientific, USA) on a DB-5MS capillary column ( $30 \mathrm{~m} \times 0.25 \mathrm{~mm}$ i.d.; $0.25 \mu \mathrm{m}$ film thickness). High purity helium (> $99.999 \%$ ) was utilized as the carrier gas under a constant flow rate of $1.0 \mathrm{~mL} / \mathrm{min}$. The inlet temperature was set at $250^{\circ} \mathrm{C}$. The initial temperature of the oven was $50^{\circ} \mathrm{C}$ for $1 \mathrm{~min}$ and it was increased to $250^{\circ} \mathrm{C}$ at a rate of $10^{\circ} \mathrm{C} / \mathrm{min}$ for $5 \mathrm{~min}$. The injection mode was splitless. The mass spectrometer was operated in electron ionization mode, and the electron energy was set at $70 \mathrm{eV}$. The mass spectra were obtained using the full scan mode with a mass scan range of 33-450 amu. The solvent delay time was 0.5 minute. The operating system was Xcalibur (v. 2.2, Thermo-Fisher Scientific).

\subsection{Statistical analysis}

Statistical significance for comparisons among the seven trees was determined using ANOVA followed by Duncan's post-hoc multiple comparison test at $P<0.05$. The rhizosphere bacterial community distances were calculated using Bray-Curtis by the function vegdist in the Vegan package in $\mathrm{R}$ (Oksanen et al. 2020). Principal coordinate analysis (PCoA) based on Bray-Curtis (permutation $=999$ ) was performed to compare the differences in rhizosphere microbial community among the seven tree varieties. In order to analyze microbial community diversity, Shannon indices and richness were analyzed by using the Vegan package in R (Dixon, 2003). Following Zanne et al. (2014), we used Phylomatic v3 (http://phylodiversity.net/phylomatic/) to obtain a phylogeny for our sampled trees, and the phylogenetic distances between each tree variety was calculated by the function cophenetic in the R package Picante (Kembel et al. 2010). The correlation between the dissimilarity matrix (Bray-Curtis distance) of the bacterial community and the plants' phylogenetic distance matrix were tested by Mantel tests, and their relationships were tested by linear regressions.

We used RandomForest and other packages to analyze the importance of microbial taxa in relation to the suspension of fungal pathogens by calculating the important value and cross-test. The correlation between the relative abundance of different microbial taxa and the inhibition rate of fungal pathogens was analyzed by linear regression. The network of co-occurrence of ASVs (from random forest indicator microbes) based on the Spearman correlation coefficient $|r| \geq 0.6$ and $P<0.05$ analysis to explore potential strong interaction among indicator microbes. Network visualization and topological parameters were obtained using Cytoscape v.3.8.2. 


\subsection{Accession numbers}

All 16S rRNA gene sequencing data were deposited in Sequence Read Archive (SRA) database under the accession number of PRJNA788786.

\section{Results}

\subsection{Suppression of fungal pathogens by rhizosphere bacterial communities from different tree varieties}

Rhizosphere bacterial communities from seven tree varieties showed significant suppression of three fungal pathogens compared to CK without rhizosphere bacteria, and this effect significantly differed among the tree varieties (Fig. 1a-d). For the antagonism experiment, the rhizosphere bacterial community associated with camphor trees showed the strongest pathogen suppression with a rate of $43.7 \%$, five times higher than that of cedar (Fig. 1a; Figs. S2a). In the binary separation experiment where fungal pathogens had no direct contact with bacterial, the camphor rhizosphere still showed the strongest pathogen suppression: in order of camphor > cypress > pterocarya > metasequoia > cedar (Fig. 1b and Fig. S2a). Lastly, we integrated the pathogen suppression of both binary separation and antagonism experiments, and found that the camphor rhizosphere had the strongest suppressive effect on fungal pathogens, followed by cypress, pterocarya, metasequoia, liriodendron, Italian poplar, and cedar was the weakest. Interestingly, Alternaria alternata had the highest susceptibility to rhizosphere suppression over the seven tree varieties, and Fusarium oxysporum had the lowest (Fig. 1c). The immediate inhibitory effect of rhizosphere bacterial suspensions on germination of $F$. oxysporum spores was tested, and this suppression was still significantly different among the seven tree varieties (Fig. S2b).

\subsection{Rhizosphere microbial communities from the different tree varieties}

Across all the samples, we obtained a total of 1,149,769 high-quality bacterial sequencing reads $(45,949$ to 68,852 sequences for each sample) that were classified to 132,324 ASVs. The alpha-diversity level of the bacterial community in Italian poplar rhizospheres was higher than that of other tree varieties $(P<$ 0.05), and that from the cedar rhizosphere was the lowest (Fig. 2a). We further measured the absolute abundance of rhizosphere bacterial communities using fluorogenic qPCR. Through comparative analyses across tree varieties, the highest bacterial copy numbers were detected in the liriodendron rhizosphere, followed by pterocarya, Italian poplars, camphor, and cedar. The significance of this trend was confirmed by one-way AVOVA analysis on rhizosphere bacterial abundances, showing significant effect of tree varieties as well (Fig. 2b).

The phylogenetic distance between each tree variety was calculated by the cophenetic function. Linear regression analysis of rhizosphere microbial community dissimilarities and the plant phylogenetic 
distance, showed that an increase in plant phylogenetic distance led to higher dissimilarities of rhizosphere bacterial community (Fig. $2 \mathrm{c}$, Mantel $r=0.468, P<0.05$ ). Moreover, the dissimilarities in rhizosphere bacterial community of different tree varieties had significant correlation with pathogen suppression, indicating that the differences in pathogen suppression by different tree varieties could be attributed to dissimilarities in rhizosphere bacterial communities (Fig. $2 d, P<0.001$ ).

\subsection{Changes in rhizosphere microbial composition of different tree varieties}

Multiple comparisons analysis revealed that tree varieties had significant difference in rhizosphere bacterial composition at the phylum level. Among the five most abundant phyla (total abundance > $87.3 \%$ ). Proteobacteria had the highest relative abundance at $32.6 \%$, followed by Acidobacteria $(23.4 \%)$, Actinobacteria (19.1\%), Chloroflexi (7.40\%), and Rokubacteria (4.61\%). The relative abundance of Proteobacteria was highest in the cedar rhizosphere, but there was no difference among the other six tree varieties. For Acidobacteria, there was higher abundance in camphor and cypress rhizospheres. The relative abundance of Actinobacteria was highest in the cedar rhizosphere, and Chloroflexi was highest in Italian poplars. For Rokubacteria, the relative abundance was highest in the metasequoia rhizosphere, but lowest in the cedar rhizosphere (Fig. 3a).

\subsection{Tree rhizosphere microbes associated with fungal pathogen suppression}

The 'Random Forests' machine learning algorithm was employed to determine the importance of rhizosphere bacterial composition across the seven tree varieties with respect to fungal suppression. The model analysis explained $60.6 \%$ of bacterial community variance with the inhibition of fungal pathogens, and 25 important bacterial families were identified using 10-fold cross-validation based on the percentage growth rate of mean square error (\%IncMSE) (Liaw and Wiener, 2002) (Fig. S3 and Table S2). The heatmap further revealed enrichment of Propionibacteriaceae, Phycisphaeraceae, Rokubacteriales, Candidatus Kaiserbacteria, Blastocatellaceae, while uncultured in Acidimicrobiia, uncultured in Acidobacteriales and Saccharimonadales, unclassified in Acidimicrobiia, and uncultured in Frankiales became less in cypress, camphor and pterocarya rhizospheres with strong fungal pathogen suppression. The relative abundance of Dongiaceae, Geodermatophilaceae, Pyrinomonadaceae and mle1-27 was extremely high in the camphor rhizosphere, while that in cedar soil was lower or even absent. However, the relative abundance of Bacillaceae, Micropepsaceae and Acidothermaceae showed great enrichment in the cedar rhizosphere (Fig. 3b).

Linear regression analysis verified that the relative abundances of Propionibacitraceae $(P<0.001)$, Phycisphaeraceae $(P<0.01)$, Rokubacteriales $(P<0.05)$, Candidatus Kaiserbacteria $(P<0.01)$, Blastocatellaceae $(P<0.01)$, Dongiaceae $(P<0.001)$, Geodermatophilaceae $(P<0.01)$, Pyrinomonadaceae $(P<0.001)$, and mle1-27 $(P<0.01)$ were positively correlated with fungus suppression, but uncultured in Acidimicrobiia $(P<0.05)$, uncultured in Acidobacteriales $(P<0.01)$, 
unclassified in Acidimicrobiia $(P<0.05)$, Saccharimonadales $(P<0.05)$, uncultured in Frankiales $(P<$ 0.01), and unknown in Gammaproteobacteria Incertae Sedis $(P<0.05)$ had negative correlation (Fig. S4).

\subsection{The network of indicated microbes}

Network analysis explored the patterns of co-occurrence of indicative bacterial groups at ASV level and their influence on the inhibition of fungal pathogens. Six modules were clustered based on correlations of bacterial groups with suppression of fungal pathogens. Module 3 was negatively correlated with fungal suppression but the others presented the opposite trends (|Spearman coefficient| $>0.6, P<0.05$ ) (Fig. 4a). The key microbial taxa $(K)$ were defined as those with high values of degree $(>60)$ and closeness centrality (>0.3) in the network (Xiong et al. 2020), and were divided into five taxa according to modularity. All other microbes were defined as non-key taxa (NK). The ASVs included in each group of taxa are detailed in Table S4. Further analysis showed that among the key taxa that were positively correlated with the inhibition of fungal pathogens, compared with the $\mathrm{K} 1$ and $\mathrm{K} 5$ taxa, the $\mathrm{K} 0$ and $\mathrm{K} 4$ showed stronger inhibition of fungal pathogens. However, both $\mathrm{K} 1$ and $\mathrm{K} 5$ enhanced the inhibition of fungal pathogens by affecting K0. Interestingly, K3 was negatively correlated with fungal inhibition, and could be competed out by other key taxa. The non-key taxa had less impact on the inhibition of fungal pathogens. In summary, the cooperation and competition between key taxa had a decisive influence on the inhibition of fungal pathogens (Fig. 4b).

\subsection{Effects of tree root exudates on rhizosphere microbial communities}

In total, 34 components were detected in the root exudates. Cypress contained the most diverse components (15), followed by liriodendron and pterocarya, while Italian poplar had the fewest components (Fig. S5). The main components in root exudates were $n$-hexadecanoic acid, octadecanoic acid, 2,4-di-tert-butylphenol and 7,9-di-tert-butyl-1-oxaspiro(4,5)deca-6,9-diene-2,8-dione (total abundance $>48.6 \%$ ). There were significant differences in abundances among the different tree varieties. These three components had the lowest abundance in root exudates of cedar, while the abundance of octadecanoic acid was highest in root exudates of metasequoia and camphor.

Correlation heatmap analysis found that cis-13-octadecenoic acid, $1,1,3,3,5,5,7,7,9,9,11,11,13,13,15,15$ hexadecamethyl octasiloxane, and octadecamethyl cyclononasiloxane were positively correlated with microbes that had negative correlation with fungal pathogen suppression, in families such as Acidothermaceae, and the unclassified families, Acidimicrobiia and Micropepsaceae. However, these components were significantly negatively correlated with alpha diversity and gene copy number. Some of the indicated microbes were positively correlated with fungal pathogen suppression. The compounds 9,12,15-octadecatrienoic acid ethyl ester (Z,Z,Z), 1-(1,5-dimethyl-4-hexenyl)-4-methyl-benzene, 14isopropylpodocarpa-8,11,13-triene-7,13-diol, aR-turmerone, linoleic acid ethyl ester, 3-(1,5-dimethyl-4hexenyl)-6-methylene-cyclohexene, turmerone and 5-(1,5-dimethyl-4-hexenyl)-2-methyl-1,3-cyclohexadiene were significantly negatively correlated with Micropepsaceae, an unclassified family in Acidimicrobiia 
and Saccharimonadales, but positively correlated with Solibacteraceae_(Subgroup_3) and Blastocatellaceae. octadecanoic acid and n-hexadecanoic acid were obviously positively correlated with Rokubacteriales, KF-JG30-B3, Dongiaceae and Pyrinomonadaceae, Thus, the differences in acid and hydrocarbon content in tree root exudates was an important factor in the dissimilarities between bacterial communities in the tree rhizospheres (Fig. 5).

\section{Discussion}

Fungal pathogens living in soil could infect plant roots for pathopoiesis, but rhizosphere microorganisms were found to produce antifungal substances, volatile organics and soluble compounds near the roots to protect plants against invading fungal pathogens (Garbeva et al. 2011a; Liu and Brettell, 2019). The extended lifespan of most trees, compared to crop plants results in long-term stress from soil fungal pathogens on tree roots (Bennett et al. 2011). In the present study, we found that rhizosphere microbes associated with various tree varieties had strong inhibitory effects on fungal pathogens, suggesting a protective role in host tree health. Three fungal pathogens, Fusarium oxysporum, Rhizoctonia solani and Alternaria alternata, were tested by separation and in vitro antagonism assays and results showed that rhizosphere microbes from different tree varieties were significantly different in their capacity to suppress fungal growth, suggesting that differences in rhizosphere composition were responsible for the variations in resistances of tree varieties to stress from soil-borne pathogens. Camphor and cypress rhizospheres had the strongest inhibitory effect on the fungi, while Italian poplars and cedar rhizosphere had the least. Our study highlighted discrepancies in rhizosphere resistances of mingled afforestation to maintain sustainability of forest health, and provided new insights into the mechanism of rhizosphere defense of trees to bio-stress (Massart et al. 2015; Solís-García et al. 2021).

The sequencing data presented here revealed that the tree varieties had a greater influence on the microbial composition of the rhizospheres than their microbial diversity and abundance. The phylogenetic distances between the trees were significantly correlated with the dissimilarities in rhizosphere bacterial composition. This result implied that different trees were equipped with individual rhizosphere strategies for recruiting specific microbes, thus resulting in a unique functional assemblage of microbial communities in the rhizosphere (Berendsen et al. 2012b). Detailed analyses of rhizosphere microbial composition showed that Proteobacteria, Acidobacteria and Actinobacteria were the most abundant families in the rhizospheres of the seven tree varieties, which corresponded with previous studies on pine and Chinese fir (Lladó et al. 2018; Wang et al. 2018). Still, there were significant differences in the relative abundances among tree varieties. For example, compared with broad-leaved trees, within the five most abundant phyla (total abundance $>83.8 \%$ ), the relative abundance of Proteobacteria, Acidobacteria and Actinobacteria in conifers was higher, but the abundance of Chloroflexi and Rokubacteria was lower, resulting in significant dissimilarities in microbial communities between both tree types. Modifying the rhizosphere microbiota for different tree varieties opens up new avenues to recruit the help of beneficial microbes in maintaining forest health. 
Increasing evidence shows how a potential pathogen attack can induce plants to produce substance that promote the growth and activity of specific rhizosphere microbes to reinforce resistance to fungal pathogens (Gómez Expósito et al. 2017; Schulz-Bohm et al. 2018). These microbes function by the production of antifungal substances, competition for space and resources, and systemic metabolic regulation of plant immunity (Chapelle et al. 2016; Niu et al. 2017). Random forest model analysis of our results showed that bacterial families like Propionibacteriaceae, Phycisphaeraceae and Rokubacteria were positively correlated with rhizosphere suppression of fungal pathogens. Research revealed that soil bacteria from Rokubacteria encoded pathways for production of secondary metabolites with antifungal potentiality that may also activate other microbes for pathogen suppression (Crits-Christoph et al. 2018; Sharrar et al. 2020).

The co-occurrence of networks demonstrates the dominance of positive correlations among interaction in the rhizosphere microbial community. Some key taxa, such as K0 and K4 (ASVs mainly belonging to Blastocatellaceae, Pyrinomonadaceae and Rokubacteria), were positively related to rhizosphere suppression of fungal pathogens, and they showed cooperative relationships with other taxa. This interactive process can strengthen the cooperation between members of the soil microbiota, consequently triggering the production of a wider range of antifungal metabolites (Niu et al. 2017). Bacterial strains that lack inhibitory activity against pathogens are likely to interact synergistically as part of an extra functional microbiome to boost suppression of pathogen growth (De Boer et al. 2005). However, the uncultured group in Acidobacteriales, and Saccharimonadales showed a negative correlation with pathogens suppression. For example, in the cedar rhizosphere, their high relative abundance in the microbial community may occupy an important niche, consequently reducing colonization by the above key microbes with cooperative ability. Therefore, some key microbes in the rhizosphere may have synergistic effects in reducing pathogen activity, and this cooperative relationship may be reinforced in the rhizosphere for broader disease control (Bakker et al. 2018b; Bibi et al. 2018; Liu et al. 2020).

Root exudates can induce the enrichment of beneficial taxa in the rhizosphere community, which is essential for achieving tolerance to biotic and abiotic stresses (Doornbos et al. 2012; Stringlis et al. 2018). For example, benzoxazinoids can attract beneficial microorganisms and change the composition and structure of the rhizosphere microbial communities to respond to stress (Neal et al. 2012; Cotton et al. 2019). In the present study, we found that the content of some root exudate compounds such as octadecanoic acid, 2,6,11-trimethyl dodecane and hexadecanoic acid ethyl ester were higher in the camphor rhizosphere. Notably, these components positively correlated with microbes that had key roles in pathogen suppression. However, in the cedar rhizosphere, the content of cis-13-octadecenoic acid, octadecamethyl-cyclononasiloxane, 2,5-dimethyl-benzaldehyde, and octasiloxane were higher, which induced the enrichment of Saccharimonadales, uncultured family in Acidimicrobiia, uncultured family in Acidobacteriales, and Micropepsaceae with negative effects on pathogen suppression. This suggested that the bacterial composition of the tree rhizospheres induced by root exudates plays a mediating role in rhizosphere resistance (Trivedi et al. 2017a; Abbasi et al. 2021). The significant correlations between rhizosphere microbial diversity and tree root exudates further supported this bioactive effect on the 
rhizosphere microbiota for responding to pathogen stress (Yang et al. 2014; Li et al. 2019). However, in the laboratory culture experiment, it is difficult to clearly separate the bidirectional effects of rhizosphere microbe-plant interactions under soil-borne pathogen stress (Fierer, 2017a; Kerdraon et al. 2019). Consequently, the mechanism of how root exudate components alter rhizosphere microbial composition to target biostressors should be further examined with more targeted experimental designs.

\section{Conclusions}

In the current study, we determined the characteristics of rhizosphere microbiomes from four broadleaved and three coniferous tree varieties in response to soil-borne fungal pathogens. The results showed that rhizosphere microbiota of various tree varieties had strong inhibitory effects on fungal pathogens, but there were significant differences among the tree varieties. Some bacterial families, such as Propionibacteriaceae, Phycisphaeraceae and Rokubacteria were enriched in the rhizospheres of trees with high suppression on fungal pathogens. Furthermore, specific components in tree root exudates induced the recruitment of key rhizosphere microbes to strengthen the cooperation within microbial community to suppress fungal pathogens. Thus, our study advances the understanding of microbial mechanism behind the advantages of diverse trees planting to maintain forest ecosystem health.

\section{Declarations}

\section{Acknowledgments}

This work was supported by the National Natural Science Foundation of China $(42011045,32122056)$, and the Excellent Youth Foundation of Jiangsu Province (BK20190040).

\section{Author's contributions}

Li Yu: conducted data curation, methodology, writing-original draft. Xiaogang Li: conceived the project, designed the experiments and review the manuscript; Haiyun Zi: performed data curation, software and writing-review. Hongguang Zhu: implemented methodology. Yangwenke Liao: review the manuscript

\section{Declarations of interest}

The authors have no relevant financial or non-financial interests to disclose

\section{References}

Abbasi S, Spor A, Sadeghi A, Safaie N (2021) Streptomyces strains modulate dynamics of soil bacterial communities and their efficacy in disease suppression caused by Phytophthora capsici. Sci Rep-uk 11:9317. http://doi.org/10.1038/s41598-021-88495-y.

Baetz U, Martinoia E (2014) Root exudates: the hidden part of plant defense. Trends Plant Sci 19:90-98. http://doi.org/10.1016/j.tplants.2013.11.006. 
Bakker PAHM, Berendsen RL, Van Pelt JA, Vismans G, Yu K, Li E, Van Bentum S, Poppeliers SWM, Sanchez Gil JJ, Zhang H, Goossens P, Stringlis IA, Song Y, de Jonge R, Pieterse CMJ (2020a) The soilborne identity and microbiome-assisted agriculture: looking back to the future. Mol Plant 13:13941401. http://doi.org/10.1016/j.molp.2020.09.017.

Bakker PAHM, Pieterse CMJ, de Jonge R, Berendsen RL (2018b) The soil-borne legacy. Cell 172:11781180. http://doi.org/10.1016/j.cell.2018.02.024.

Ben Amira M, Lopez D, Triki Mohamed A, Khouaja A, Chaar H, Fumanal B, Gousset-Dupont A, Bonhomme L, Label P, Goupil P, Ribeiro S, Pujade-Renaud V, Julien J, Auguin D, Venisse J (2017) Beneficial effect of Trichoderma harzianum strain Ths97 in biocontrolling Fusarium solani causal agent of root rot disease in olive trees. Biol Control 110:70-78. http://doi.org/10.1016/j.biocontrol.2017.04.008.

Bennett AJ, Bending GD, Chandler D, Hilton S, Mills P (2012) Meeting the demand for crop production: The challenge of yield decline in crops grown in short rotations. Biological Reviews Of The Cambridge Philosophical Society 87:52-71. http://doi.org/10.1111/j.1469-185X.2011.00184.x.

Berendsen RL, Vismans G, Yu K, Song Y, de Jonge R, Burgman WP, Burmølle M, Herschend J, Bakker PAHM, Pieterse CMJ (2018a) Disease-induced assemblage of a plant-beneficial bacterial consortium. ISME J 12:1496-1507. http://doi.org/10.1038/s41396-018-0093-1.

Berendsen RL, Pieterse CMJ, Bakker PAHM (2012b) The rhizosphere microbiome and plant health. Trends Plant Sci 17:478-486. http://doi.org/https://doi.org/10.1016/j.tplants.2012.04.001.

Bibi F, Strobel G, Naseer M, Yasir M, Alghamdi A, Azhar E (2018) Microbial flora associated with the Halophyte-Salsola imbricate and its biotechnical potential. Front Microbiol 9:65.

http://doi.org/10.3389/fmicb.2018.00065.

Bokulich NA, Kaehler BD, Rideout JR, Dillon M, Bolyen E, Knight R, Huttley GA, Gregory Caporaso J (2018) Optimizing taxonomic classification of marker-gene amplicon sequences with QIIME 2's q2-featureclassifier plugin. Microbiome 6:90. http://doi.org/10.1186/s40168-018-0470-z.

Cha J, Han S, Hong H, Cho H, Kim D, Kwon Y, Kwon S, Crüsemann M, Lee Y, Kim J, Giaever G, Nislow C, Moore B, Thomashow L, Weller D, Kwak Y (2015) Microbial and biochemical basis of a Fusarium wiltsuppressive soil. ISME J 10: 119-129. http://doi.org/10.1038/ismej.2015.95.

Chapelle E, Mendes R, Bakker PAHM, Raaijmakers JM (2016) Fungal invasion of the rhizosphere microbiome. ISME J 10:265-268. http://doi.org/10.1038/ismej.2015.82.

Chen DL, Wang XX, Zhang W, Zhou ZG, Ding CF, Liao YWK, Li XG (2020) Persistent organic fertilization reinforces soil-borne disease suppressiveness of rhizosphere bacterial community. Plant Soil 452:313328. http://doi.org/10.1007/s11104-020-04576-3. 
Chliyeh M, Msairi S, Ouazzani Touhami A, Benkirane R, Douira A (2017) Detection of Fusarium solani as a pathogen causing root rot and wilt diseases of young olive trees in Morocco. Annual Research \& Review in Biology 13:1-7. http://doi.org/10.9734/ARRB/2017/33744.

Corral-Lugo A, Daddaoua A, Ortega A, Espinosa-Urgel M, Krell T (2016) Rosmarinic acid is a homoserine lactone mimic produced by plants that activates a bacterial quorum-sensing regulator. Sci Signal 9:ra1. http://doi.org/10.1126/scisignal.aaa8271.

Cotton TEA, Pétriacq P, Cameron DD, Meselmani MA, Schwarzenbacher R, Rolfe SA, Ton J (2019) Metabolic regulation of the maize rhizobiome by benzoxazinoids. ISME J 13:1647-1658. http://doi.org/10.1038/s41396-019-0375-2.

Crits-Christoph A, Diamond S, Butterfield CN, Thomas BC, Banfield JF (2018) Novel soil bacteria possess diverse genes for secondary metabolite biosynthesis. Nature 558:440-444.

http://doi.org/10.1038/s41586-018-0207-y.

De Boer W, Folman LB, Summerbell RC, Boddy L (2005) Living in a fungal world: impact of fungi on soil bacterial niche development. Fems Microbiol Rev 29:795-811.

http://doi.org/10.1016/j.femsre.2004.11.005.

DeSantis T, Philip H, Larsen N, Rojas M, Brodie E, Keller K, Huber T, Dalevi D, Hu P, Andersen G (2006) Greengenes, a chimera-checked 16S rRNA gene database and workbench compatible with ARB. Appl Environ Microb 72:5069-5072. http://doi.org/10.1128/AEM.03006-05.

Dixon P (2003) VEGAN, a package of R functions for community ecology. J Veg Sci 14:927-930. http://doi.org/10.1658/11009233(2003)014[0927:VAPORF]2.0.CO;2.

Doornbos RF, van Loon LC, Bakker PAHM (2012) Impact of root exudates and plant defense signaling on bacterial communities in the rhizosphere. A review. Agron Sustain Dev 32:227-243.

http://doi.org/10.1007/s13593-011-0028-y.

Duan J (2014) Allelopathy and the allelopathic substance in root exudates of pinus massoniana. [dissertation/master's thesis]. Jiangxi Agricultural University.

Nanchang.https://kns.cnki.net/KCMS/detail/detail.aspx?

dbname $=$ CMFD201501\&filename $=1014396251$.nh.

Gómez Expósito R, de Bruijn I, Postma J, Raaijmakers JM (2017) Current insights into the role of rhizosphere bacteria in disease suppressive soils. Front Microbiol 8:2529.

http://doi.org/10.3389/fmicb.2017.02529.

Fierer N (2017a) Embracing the unknown: disentangling the complexities of the soil microbiome. Nat Rev Microbiol 15:579-590. http://doi.org/10.1038/nrmicro.2017.87. 
Fierer N, Jackson J, Vilgalys R, Jackson R (2005b) Assessment of soil microbial community structure by use of taxon-specific quantitative PCR assays. Appl Environ Microb 71:4117-

4120. http://doi.org/10.1128/AEM.71.7.4117-4120.2005.

Garbeva P, Hol WHG, Termorshuizen AJ, Kowalchuk GA, De Boer W (2011a) Fungistasis and general soil biostasis - A new synthesis. Soil Biol Biochem 43:469-477. http://doi.org/10.1016/j.soilbio.2010.11.020.

Garbeva P, Hordijk K, Gerards S, De Boer W (2013b) Volatiles produced by the mycophagous soil bacterium Collimonas. Fems Microbiol Ecol 87:639-649. http://doi.org/10.1111/1574-6941.12252.

He JZ, Xu ZH, Hughes J (2006) Molecular bacterial diversity of a forest soil under residue management regimes in subtropical Australia. Fems Microbiol Ecol 55:38-47. http://doi.org/10.1111/j.15746941.2005.00006.x.

Hol WHG, Garbeva P, Hordijk C, Hundscheid PJ, Gunnewiek PJAK, Van Agtmaal M, Kuramae EE, De Boer W (2015) Non-random species loss in bacterial communities reduces antifungal volatile production. Ecology 96:2042-2048. http://doi.org/10.1890/14-2359.1.

Hu J, Wei Z, Kowalchuk G, Xu Y, Shen Q, Jousset A (2020) Rhizosphere microbiome functional diversity and pathogen invasion resistance build up during plant development. Environ Microbiol 22:5005-5018. http://doi.org/10.1111/1462-2920.15097.

Hu L, Robert CAM, Cadot S, Zhang X, Ye M, Li B, Manzo D, Chervet N, Steinger T, van der Heijden MGA, Schlaeppi K, Erb M (2018) Root exudate metabolites drive plant-soil feedbacks on growth and defense by shaping the rhizosphere microbiota. Nat Commun 9:2738. http://doi.org/10.1038/s41467-018-05122-7.

Jousset A, Bienhold C, Chatzinotas A, Gallien L, Gobet A, Kurm V, Küsel K, Rillig MC, Rivett DW, Salles JF, van der Heijden MGA, Youssef NH, Zhang X, Wei Z, Hol WHG (2017) Where less may be more: how the rare biosphere pulls ecosystems strings. ISME J 11:853-862. http://doi.org/10.1038/ismej.2016.174.

Kembel S, Cowan P, Helmus M, Cornwell W, Morlon H, Ackerly D, Blomberg S, Webb C (2010) Picante: R tools for integrating phylogenies and ecology. Bioinformatics (Oxford, England) 26:14631464. http://doi.org/10.1093/bioinformatics/btq166.

Kerdraon L, Barret M, Laval V, Suffert F (2019) Differential dynamics of microbial community networks help identify microorganisms interacting with residue-borne pathogens: the case of Zymoseptoria tritici in wheat. Microbiome 7:125. http://doi.org/10.1186/s40168-019-0736-0.

Kokalis-Burelle N, McSorley R, Wang K, Saha S, McGovern R (2017) Rhizosphere microorganisms affected by soil solarization and cover cropping in Capsicum annuum and Phaseolus lunatus agroecosystems. Appl Soil Ecol 119: 64-71. http://doi.org/10.1016/j.apsoil.2017.06.001.

Kong WL, Li PS, Wu XQ, Wu TY, Sun XR (2020) Forest tree associated bacterial diffusible and volatile organic compounds against various phytopathogenic fungi. Microorganisms 8:590. 
http://doi.org/10.3390/microorganisms8040590.

Li M, Wei Z, Wang JN, Jousset A, Friman V, Xu YC, Shen QR, Pommier T (2019) Facilitation promotes invasions in plant-associated microbial communities. Ecol Lett 22:149-158.

http://doi.org/10.1111/ele.13177.

Li XG, Garbeva P, Liu XJ, Klein Gunnewiek PJA, Clocchiatti A, Hundscheid MPJ, Wang XX, De Boer W (2020) Volatile-mediated antagonism of soil bacterial communities against fungi. Environ Microbiol 22:1025-1035. http://doi.org/10.1111/1462-2920.14808.

Liaw A, Wiener M (2002) Classification and regression by Random Forest. R News 2:18-22.

Liu HW, Brettell LE, Qiu ZG, Singh BK (2020) Microbiome-mediated stress resistance in plants. Trends Plant Sci 25:733-743. http://doi.org/10.1016/j.tplants.2020.03.014.

Liu HW and Brettell L (2019) Plant defense by VOC-induced microbial priming. Trends Plant Sci 24:187189. http://doi.org/10.1016/j.tplants.2019.01.008.

Lladó S, López-Mondéjar R, Baldrian P (2018) Drivers of microbial community structure in forest soils. Appl Microbiol Biot 102:1-8. http://doi.org/10.1007/s00253-018-8950-4.

Massart S, Martinez-Medina M, Jijakli MH (2015) Biological control in the microbiome era: Challenges and opportunities. Biol Control 89:98-108.

http://doi.org/https://doi.org/10.1016/j.biocontrol.2015.06.003.

Mendes R, Garbeva P, Raaijmakers JM (2013) The rhizosphere microbiome: significance of plant beneficial, plant pathogenic, and human pathogenic microorganisms. Fems Microbiol Rev 37:634663. https://doi.org/10.1016/j.ecoleng.2013.09.064.

Mercado-Blanco J, Abrantes I, Barra Caracciolo A, Bevivino A, Ciancio A, Grenni P, Hrynkiewicz K, Kredics L, Proença DN (2018) Belowground microbiota and the health of tree crops. Front Microbiol 9:1006. http://doi.org/10.3389/fmicb.2018.01006.

Moomaw WR, Law BE, Goetz SJ (2020) Focus on the role of forests and soils in meeting climate change mitigation goals: summary. Environ Res Lett 15:045009. http://doi.org/10.1088/1748-9326/ab6b38.

Neal AL, Ahmad S, Gordon-Weeks R, Ton J (2012) Benzoxazinoids in root exudates of maize attract Pseudomonas putida to the rhizosphere. Plos One 2012;7:e35498.

http://doi.org/10.1371/journal.pone.0035498.

Nepal P, Abt KL, Skog KE, Prestemon JP, Abt RC (2019) Projected market competition for wood biomass between traditional products and energy: a simulated interaction of US regional, national, and global forest product markets. Forest Sci 65:14-26. http://doi.org/10.1093/forsci/fxy031. 
Niu B, Paulson J, Zheng XQ, Kolter R (2017) Simplified and representative bacterial community of maize roots. P Natl Acad Sci Usa 114:2450-2459. http://doi.org/10.1073/pnas.1616148114.

Oksanen J, Blanchet FG, Friendly M, Kindt R, Legendre P, McGlinn D, Minchin P, O Hara RB, Simpson G, Solymos P, Stevens M, Szöcs E, Wagner H (2020) vegan community ecology package version 2.5-7 November 2020.

Oliva J, Redondo MÁ, Stenlid J (2020) Functional ecology of forest disease. Annu Rev Phytopathol 58:343-361. http://doi.org/10.1146/annurev-phyto-080417-050028.

Pagán E, Robles JM, Temnani A, Berríos P, Botía P, Pérez-Pastor A (2022) Effects of water deficit and salinity stress on late mandarin trees. Sci Total Environ 803:150109. http://doi.org/10.1016/j.scitotenv.2021.150109.

Raaijmakers JM, Paulitz TC, Steinberg C, Alabouvette C, Moënne-Loccoz Y (2009) The rhizosphere: a playground and battlefield for soilborne pathogens and beneficial microorganisms. Plant Soil 321:341361. http://doi.org/10.1007/s11104-008-9568-6.

Reddy CS, Sreelekshmi S, Jha CS, Dadhwal VK (2013) National assessment of forest fragmentation in India: Landscape indices as measures of the effects of fragmentation and forest cover change. Ecol Eng 60:453-464. http://doi.org/10.1016/j.ecoleng.2013.09.064.

Rodriguez PA, Rothballer M, Chowdhury SP, Nussbaumer T, Gutjahr C, Falter-Braun P (2019) Systems biology of plant-microbiome interactions. Mol Plant 12:804-821.

http://doi.org/10.1016/j.molp.2019.05.006.

Rudel TK, Meyfroidt P, Chazdon R, Bongers F, Sloan S, Grau HR, Van Holt T, Schneider L (2020) Whither the forest transition? Climate change, policy responses, and redistributed forests in the twenty-first century. Ambio 49:74-84. http://doi.org/10.1007/s13280-018-01143-0.

Ryan PR, Dessaux Y, Thomashow LS, Weller DM (2009) Rhizosphere engineering and management for sustainable agriculture. Plant Soil 321:363-383. http://doi.org/10.1007/s11104-009-0001-6.

Schmalenbach I, Korber N, Pillen K (2008) Selecting a set of wild barley introgression lines and verification of QTL effects for resistance to powdery mildew and leaf rust. TheoR Appl Genet 117:10931106. http://doi.org/10.1007/s00122-008-0847-7.

Schulz-Bohm K, Gerards S, Hundscheid M, Melenhorst J, De Boer W, Garbeva P (2018) Calling from distance: attraction of soil bacteria by plant root volatiles. ISME J 12:1252-1262. http://doi.org/10.1038/s41396-017-0035-3.

Sharrar AM, Crits-Christoph A, Méheust R, Diamond S, Starr EP, Banfield JF (2020) Bacterial secondary metabolite biosynthetic potential in soil varies with phylum, depth, and vegetation type. Mbio 11:e416e420. http://doi.org/10.1128/mBio.00416-20. 
Simko I, Atallah AJ, Ochoa OE, Antonise R, Galeano CH, Truco MJ, Michelmore RW (2013) Identification of QTLs conferring resistance to downy mildew in legacy cultivars of lettuce. Sci Rep-uk 3:2875. http://doi.org/10.1038/srep02875.

Solís-García IA, Ceballos-Luna O, Cortazar-Murillo EM, Desgarennes D, Garay-Serrano E, Patiño-Conde V, Guevara-Avendaño E, Méndez-Bravo A, Reverchon F (2021) Phytophthora Root Rot Modifies the Composition of the Avocado Rhizosphere Microbiome and Increases the Abundance of Opportunistic Fungal Pathogens. Front Microbiol 11:574110. http://doi.org/10.3389/fmicb.2020.574110.

Stringlis IA, Yu K, Feussner K, de Jonge R, Van Bentum S, Van Verk MC, Berendsen RL, Bakker PAHM, Feussner I, Pieterse CMJ (2018) MYB72-dependent coumarin exudation shapes root microbiome assembly to promote plant health. P Natl Acad Sci Usa 115:E5213-

E5222. http://doi.org/10.1073/pnas.1722335115.

Syed Ab Rahman SF, Singh E, Pieterse CMJ, Schenk PM (2018) Emerging microbial biocontrol strategies for plant pathogens. Plant Sci 267:102-111. https://doi.org/10.1016/j.plantsci.2017.11.012.

Trivedi P, Delgado-Baquerizo M, Trivedi C, Hamonts K, Anderson IC, Singh B (2017a) Keystone microbial taxa regulate the invasion of a fungal pathogen in agro-ecosystems. Soil Biol Biochem 111:1014. http://doi.org/10.1016/j.soilbio.2017.03.013.

Trivedi P, Leach JE, Tringe SG, Sa T, Singh BK (2020b) Plant-microbiome interactions: from community assembly to plant health. Nat Rev Microbiol 18:607-621. http://doi.org/10.1038/s41579-020-0412-1.

Veras HNH, Rodrigues FFG, Colares AV, Menezes IRA, Coutinho HDM, Botelho MA, Costa JGM (2012) Synergistic antibiotic activity of volatile compounds from the essential oil of Lippia sidoides and thymol. Fitoterapia 83:508-512. http://doi.org/10.1016/j.fitote.2011.12.024.

Wang Q, Wang C, Yu WW, Turak A, Chen DW, Huang Y, Ao JH, Jiang Y, Huang ZR (2018) Effects of nitrogen and phosphorus inputs on soil bacterial abundance, diversity, and community composition in Chinese fir plantations. Front Microbiol 9:1543. http://doi.org/10.3389/fmicb.2018.01543.

Wei Z, Friman VP, Pommier T, Geisen S, Jousset A, Shen QR (2020) Rhizosphere immunity : targeting the underground for sustainable plant health management. Front Agric Sci Eng 7:317-328. http://doi.org/10.15302/J-FASE-2020346.

Xiong C, Zhu YG, Wang JT, Singh B, Han LL, Shen JP, Li PP, Wang GB, Wu CF, Ge AH, Zhang LM and He JZ (2020) Host selection shapes crop microbiome assembly and network complexity. New Phytol 229:10911104. http://doi.org/10.1111/nph.16890.

Yang M, Zhang Y, Qi L, Mei XY, Liao JJ, Ding XP, Deng WP, Fan LM, He XH, Vivanco J, Li CY, Zhu YQ, Zhu SS (2014) Plant-plant-microbe mechanisms involved in soil-borne disease suppression on a maize and pepper intercropping system. Plos One 9:e115052. http://doi.org/10.1371/journal.pone.0115052 . 
Yin CT, Casa VJM, Schlatter DC, Hagerty CH, Hulbert SH, Paulitz TC (2021) Rhizosphere community selection reveals bacteria associated with reduced root disease. Microbiome 9:86. http://doi.org/doi: 10.1186/s40168-020-00997-5.

Zamora Ballesteros C, Diez J, Martín-García J, Witzell J, Solla A, Ahumada R, Capretti P, Cleary M, Drenkhan R, Dvořák M, Recuenco M, Fernández MM, Ghelardini L, Gonthier P, Hernandez-Escribano L, loos R, Svetlana M, Martínez-Álvarez P, Muñoz-Adalia EJ, Hantula J (2019) Pine pitch canker (PPC): pathways of pathogen spread and preventive measures. Forests 10:1158. http://doi.org/10.3390/f10121158.

Zanne AE, Tank DC, Cornwell WK, Eastman JM, Smith SA, FitzJohn RG, McGlinn DJ, O Meara BC, Moles AT, Reich PB, Royer DL, Soltis DE, Stevens PF, Westoby M, Wright IJ, Aarssen L, Bertin RI, Calaminus A, Govaerts R, Hemmings F, Leishman MR, Oleksyn J, Soltis PS, Swenson NG, Warman L, Beaulieu JM (2014) Three keys to the radiation of angiosperms into freezing environments. Nature 506:89-92. http://doi.org/10.1038/nature12872.

\section{Figures}

\section{Figure 1}

Suppression of fungal pathogens by rhizosphere bacterial communities from different tree varieties. Mycelial diameters of fungal pathogens exposed to suspensions of rhizosphere microbiota from seven tree varieties (water control, CK) in antagonism (a) and separation experiments (b). The total average inhibition rates of soil bacterial suspension among seven tree varieties on three fungal pathogens (c). Different letters above the bars indicate significant differences in the means among the treatments $(P$ $<0.05$ ). Responses of fungal pathogens growth to soil bacterium suspension (d). CK (control, no bacterium suspension), Cy (cypress), Ca (camphor), Lir (liriodendron), Pt (pterocarya), Itp (Italian poplar), $\mathrm{Ce}$ (cedar), Me (metasequoia).

\section{Figure 2}

Richness indices of rhizosphere bacterial community in different tree varieties (a). Total abundance of bacterial communities in tree rhizospheres by qPCR (b). Correlation between plant phylogenetic distances and microbial community dissimilarities (c). Correlation between microbial community dissimilarities and inhibition rate of fungi (d). Different letters above the bars indicate statistically significant differences ( $P$ $<0.05, \mathrm{n}=3$ ), according to Duncan's multiple comparison test.

\section{Figure 3}


Relative abundances of bacterial phyla in rhizospheres of different tree varieties. 'Others' = phyla with relative abundance $<1 \%$ (a). The top 25 microbes related to inhibition of fungal pathogens were identified by applying random forest regressions. Selected microbes are ranked in descending order of importance to the accuracy of the model, ' + ' = positive correlation, ' $'$ '= negative correlation. Heatmap shows the relative abundance of the top 25 indicated microbes (b). ${ }^{*} P<0.05, * \star P<0.01,{ }^{*} * * P 0.001$, by Duncan's multiple comparison test $(n=3)$.

\section{Figure 4}

Network co-occurrence analysis of the relationship between selected microbes and fungal inhibition. (|Spearman coefficient $\mid>0.6, P<0.05$ ). Modular network analysis of indicated microbes. Different colored dots represent different modules (a). Network co-occurrence analysis of the influence of key taxa on the inhibition rate of fungal pathogens (b). Red shows positive correlation, green shows negative correlation and the line weight represents degree of correlation (the thicker the line, the stronger the correlation). Circles represent key taxa (K), squares represent non-key taxa (NK) and triangles represent inhibition rate of fungi (IRF).

\section{Figure 5}

Heatmap of the relationship between root exudates and important microbes, alpha diversity and gene copy number. ${ }^{*} P<0.05,{ }^{*} P<0.01,{ }^{\star} * \star P<0.001$ by Spearman.

\section{Supplementary Files}

This is a list of supplementary files associated with this preprint. Click to download.

- SupplementaryInformation.docx 